\title{
Artelogie
}

artelogie Recherche sur les arts, le patrimoine et la littérature de l'Amérique latine

13 | 2019

Violeta Parra: authenticité, primitivisme et processus d'exotisme chez les artistes latino-américains.

\section{Para la reina... apenas una carpa. Innovación y primitivismo en Violeta Parra y su experiencia en La Carpa de la Reina.}

Ariel Mamani

\section{(2) OpenEdition}

Journals

Edición electrónica

URL: http://journals.openedition.org/artelogie/2906

DOI: $10.4000 /$ artelogie.2906

ISSN: 2115-6395

Editor

Association ESCAL

Referencia electrónica

Ariel Mamani, « Para la reina... apenas una carpa. Innovación y primitivismo en Violeta Parra y su experiencia en La Carpa de la Reina. », Artelogie [En línea], 13 | 2019, Publicado el 07 enero 2019, consultado el 01 mayo 2019. URL : http://journals.openedition.org/artelogie/2906 ; DOI : 10.4000/ artelogie.2906

Este documento fue generado automáticamente el 1 mayo 2019.

Association ESCAL 


\title{
Para la reina... apenas una carpa. Innovación y primitivismo en Violeta Parra y su experiencia en La Carpa de la Reina.
}

\author{
Ariel Mamani
}

\section{Introducción}

1 Una mujer canta con rabia sobre un precario escenario montado en una carpa de circo. Afuera arrecia el viento y la lluvia. Casi no cuenta con espectadores, apenas una solitaria pareja asiste al concierto. El temporal comienza a afectar el entorno. Llueve al interior de la carpa. Una joven trata de salvar instrumentos y tapices de la furia de los elementos. Los miembros de la pareja, únicos asistentes al espectáculo, titubean y finalmente abandonan en forma atropellada el lugar. La cantora es Violeta Parra, y a pesar de todo continúa con su tarea, con mucha rabia, pero también con una enorme dignidad. Las luces de la carpa titilan y se apagan. Todo parece sucumbir. Todo. No solo la función de la carpa.

De esta forma refiere con imágenes el cineasta Andrés Wood (2011) lo que podría haber sido algunas de las noches en La Carpa Gigante de la Reina, último reducto de la artista chilena Violeta Parra. A pesar del artificio que encierra la escena, en tanto obra cinematográfica, guarda un alto grado de verosimilitud. Muchos testimonios acreditan situaciones similares, quizás sin el componente exagerado que le confiere el film, pero con igual dramatismo.

El objetivo de este trabajo es analizar la faz artística, cultural y política de las peñas folklóricas tomando como estudio de caso a La Carpa de la Reina, espacio montado por la reconocida cantautora chilena Violeta Parra meses antes de poner fin a su vida con un disparo. En un primer momento se analizará el surgimiento de las peñas folklóricas, fijando la mirada en la Peña de los Parra, sitio que resultó un arquetipo en el cual se reflejaron muchas otras experiencias similares. Posteriormente me centraré en la Carpa de 
la Reina, especie de peña montada por Violeta Parra en la periferia de Santiago de Chile en 1965. A partir de ello se buscará dar respuesta a diferentes interrogantes para determinar si La Carpa Gigante de la Reina fue continuidad y punto climático de la experiencia de peñas folklóricas de fines de los años 60 o si, en todo caso, esta idea desarrollada por la insigne cantautora chilena fue en definitiva una propuesta antagónica, tanto en el contenido como en la forma.

\section{Canción política en las peñas folklóricas}

Desde mediados de la década de 1960 las llamadas peñas folklóricas se transformaron en un fenómeno muy particular que se extendió por las principales ciudades chilenas, en un contexto político y social muy complejo y cargado de tensiones. Las peñas funcionaban generalmente en pequeños locales donde se presentaban números musicales en vivo y donde se ofrecía algo de comer y beber. Muchos de estos sitios se transformaron con el tiempo en importantes ámbitos de sociabilidad, con la asistencia de un público numeroso, aunque no masivo, y en sus diferentes variantes, se convirtieron en un espacio privilegiado para fijar, al menos desde lo simbólico, una posición política o partidaria. ${ }^{i}$

La mayoría de los artistas deseaba, además de ser escuchado en su presentación musical, interactuar con los asistentes. Lo reducido del espacio y un número no demasiado numeroso de público colaboraban en ese sentido. En cada una de las peñas, era común encontrarse a los diferentes cantautores deambular por las mesas y conversar animadamente con la concurrencia.

Dos de los hijos de Violeta Parra, Isabel y Ángel, habían residido en Europa varios años junto a su madre, desarrollando su carrera musical y artística. Los hermanos Parra retornaron a Chile en 1964 y participaron activamente de la campaña presidencial en apoyo del candidato del Frente de Acción Popular (FRAP), Salvador Allende.

7 Los espacios que podían permitir la presentación de espectáculos de raíz folklórica, como teatros o locales nocturnos, eran escasos para el tipo de música comprometida que practicaban los Parra. Es por ello que, junto a un grupo pequeño de cantautores, buscaron recrear en algún sentido a las boites de nuit parisinas, aquellos locales del barrio latino de París donde habían actuado junto a su madre durante su estadía europea.

8 En abril de 1965 se inauguró La Peña Carmen 340 en aquella una vieja casona. El local funcionaba jueves, viernes y sábado por la noche, teniendo como artistas estables al propio Ángel Parra, a su hermana Isabel, a Patricio Manns y a Rolando Alarcón. A poco de inaugurar se sumó el cantautor y director de teatro Víctor Jara.

9 La apuesta desplegada en Carmen 340 resultó innovadora para el ambiente musical y cultural de aquél entonces. Los músicos estables de La Peña interpretaban canciones comprometidas políticamente, a la vez que desarrollaban una militancia de izquierda mayoritariamente dentro del Partido Comunista de Chile. ${ }^{\text {ii }}$ El nivel de compromiso político fue indudable desde la inauguración del local, dotando de un sentido de pertenencia política no solo a los artistas sino también a un sector de los asistentes. Aquel primer núcleo de cantautores, junto a otros músicos que participaron posteriormente en la iniciativa, eran parte de lo que después se denominó Nueva Canción Chilena, un prolífico movimiento musical que se destacó tanto por su apuesta artística como por su compromiso militante con la izquierda chilena. 
10 Como base de su funcionamiento se implementó un sistema cooperativo de administración del local cimentado en una distribución equitativa entre los músicos que participaban en cada una de las noches a partir de la recaudación diaria.

11 La Peña de los Parra, como también fue conocida Carmen 340, se transformó con el tiempo en una especie de centro cultural donde se desarrollaron diversas actividades como muestras de arte, exposiciones, clases de música, talleres de artesanías y reuniones de la militancia. Tanto músicos como público identificaron a esta peña como un espacio alternativo, lo que permitía romper con los restringidos límites presentes en los circuitos estrictamente comerciales.

12 El reconocimiento recibido, y la difusión a través de la oralidad, colocaron al emprendimiento como un sitio "de moda", teñido de una buena dosis de snobismo. “(...) a la peña iba gente de hartos lados -manifestaba Marta Orrego, por ese entonces esposa de Ángel Parra y colaboradora esencial en la peña- pero los pitucos estaban a la orden del día" (VALLADARES Y VILCHES, 2014: 88).

13 Por todo lo mencionado, La Peña de los Parra desplegó una significativa influencia hacia otras experiencias que buscaron presentar un formato similar, transformándose no solo en iniciadora del fenómeno, sino que puede ser considerada como un arquetipo a seguir. “El éxito de la Peña fue enorme y muy pronto, este tipo de espectáculos proliferó por todos lados y entró en todas las capas sociales" (SANTANDER, 1984: 31). Es por ello que a partir de la experiencia de los hermanos Parra, el fenómeno de las peñas se extendió por todo Chile.

14 Es posible señalar que a fines de los años 60 se podían encontrar en Santiago peñas folklóricas que respondían a diversos modelos e ideas, pero con un claro perfil que permitía al público identificar de manera bastante clara la orientación musical, social e ideológica de cada una. De esa forma, las peñas operaban como un destacado ámbito de sociabilidad que permitía no solo acercarse a un espectáculo musical sino también a una opción estética y a una postura ideológica.

\section{El retorno de la Viola Chilensis}

15 Violeta Parra retornó a Chile en 1964, pero sin intención de quedarse en forma definitiva. Si bien era una artista admirada y respetada, no poseía el reconocimiento masivo que merecía. "La fabricación propagandística y el lanzamiento de cualquier cantante de segunda fila -afirma Víctor Casaus- ocupaba más tiempo y recursos que la divulgación de la obra artística de Violeta Parra" (CASAUS en PARRA, 2009: 23).

16 Su fuerte personalidad y la pureza de sus ideales la habían llevado a recorrer un camino muchas veces reñidos con la mercantilización de la actividad artística. De todas maneras, si bien Violeta no era una artista de gran masividad tampoco se trataba de una outsider. A través de su hermano Nicanor, y de la cercanía de la propia Violeta con el Partido Comunista, la cantautora tenía contacto con grupos de escritores, artistas plásticos e intelectuales (SÁEZ, 2016). Es verdad que su perfil no encuadraba específicamente con los parámetros predominantes en aquellos agrupamientos de artistas, entre los que podemos nombrar a Pablo Neruda, Julio Escámez, Enrique Lihn, Margot Loyola y Gonzalo Rojas (HERRERO, 2017). Su lenguaje sencillo, a veces procaz, su vestimenta humilde y campesina la exhibían con una imagen algo distante del perfil de aquellos artistas e intelectuales. 
17 Sin embargo, ese perfil de artista marginal no fue solo obra de las circunstancias, sino que muchas veces, la propia Violeta se encargó de construir esa imagen, presentándose como una simple campesina, apenas vocera de los cantos y costumbres del espacio rural.

Violeta había cantado desde niña junto a sus hermanos, como un modo de salir de las precarias condiciones de vida de su familia. ${ }^{\text {iii }}$ A mediados de la década del 50 comenzó a realizar viajes al interior de Chile con el fin de recopilar manifestaciones folklóricas y pudo hacerse de una reputación importante dentro de la Proyección Folklórica. Al mismo tiempo comenzó a componer canciones con un fuerte contenido político y a desarrollar otras actividades vinculadas a la plástica (dibujos, esculturas, textiles).

Su trayectoria estuvo plagada de dificultades para realizar una carrera acorde a sus cualidades como artista, a la vez que la escasez de apoyos económicos e institucionales fue consuetudinaria.

"A mediados de agosto de 1964 -señala Fernando Sáez- llegó a Chile, que era un hervidero político debido a la cercanía de las elecciones. El ambiente no era propicio para que recibiera ningún reconocimiento especial después de su larga ausencia" (2016: 61).

La derrota de la coalición de izquierda en las elecciones decidió a Violeta a regresar a Francia: “(...) después de que perdimos la Campaña del 64, -recordaba Adela Gallo- la Violeta me dijo, no tenemos nada que hacer aquí, vámonos para Europa" (RODRÍGUEZ, 1984: 190). Sin embargo, en París encontró dificultades para reinsertarse en sus antiguas actividades y decidió viajar a Ginebra donde Gilbert Favre, un artista bohemio suizo que había conocido años atrás en Chile y era su gran amor. Allí permanecieron juntos en un período bastante tranquilo, de mucha creatividad.

21 No obstante, Violeta ansiaba retornar a Chile. Las noticias llegadas de sus hijos y los cambios en el panorama musical chileno le intrigaban. "Ella no podía estar ajena, ausente, si se vislumbraba, por primera vez, la posibilidad de que su empecinado trabajo de tantos años pudiera obtener la acogida que creía merecer" (SÁEZ, 2016: 166).

Finalmente, Violeta Parra retornó a Chile en agosto de 1965, y el ambiente artístico que la recibió parecía ser más amable para ella que en el pasado. La movilización estudiantil, el crecimiento electoral de la izquierda, la renovación musical dentro del folklore y hasta el contexto latinoamericano dominado por la influencia de la Revolución Cubana, parecían estar del lado de la artista. Violeta "Llegó a Chile en el momento que se está produciendo un movimiento muy fuerte en lo musical -señala Carmen Oviedo- (...) que es muy diferente del folklore típico y que tiene el tremendo valor de la denuncia de una realidad social" (OVIEDO, 1991: 101).

Muchos jóvenes, algunos reunidos en torno al movimiento musical que frecuentaba las peñas, vieron en Violeta Parra una referencia esencial en la búsqueda de una profunda renovación de la música popular chilena, que intentaba reunir en partes iguales, compromiso político, raigambre popular e innovación estética. "Ella guía muchas de nuestras composiciones de la época -recuerda Patricio Manns- hace severas críticas pero también cálidos elogios, discute separadamente con cada uno de nosotros determinadas particularidades de nuestras creaciones, aconseja, impugna, estimula" (2017: 76).

24 Violeta Parra regresaba, entonces, cargada de proyectos. Gastón Soublette, amigo y colaborador en tareas de recopilación, se había encontrado con ella en el aeropuerto de Orly cuando la artista estaba viajando de retorno a Chile. La notó especialmente alegre y 
motivada: “(...) estaba feliz, -rememora Soublette- llena de planes, contenta como nunca la había visto” (SÁEZ, 2016: 166).

Una vez que hubo arribado a Santiago, Violeta se sumó al proyecto impulsado por sus hijos en la peña de la calle Carmen, además de otras múltiples actividades. Por esos días se ultimaba el lanzamiento del LP Violeta Parra (una chilena en París) Recordando a Chile que había comenzado a grabar en su anterior viaje en 1964, con muchas de las composiciones de su estadía europea.

Si bien la Peña Carmen 340 funcionaba con mucho éxito Violeta Parra no se integró del todo. La fuerte personalidad de Violeta puede haber influido en la relación con Ángel e Isabel, quienes estaban comenzando a transitar un camino propio y donde independizarse de la tutela de su portentosa madre parecía fundamental. Asimismo, el carácter cooperativo que había asumido la Peña, donde se repartían las ganancias y se decidía todo de forma grupal colisionaba con la prepotencia que Violeta solía utilizar en las cuestiones de índole organizacional. Patricio Manns recuerda que Violeta se incorporó a la peña de Carmen 340 pero dando órdenes, como asumiendo la dirección (MANNS, comunicación personal, septiembre 2017). Al parecer Ángel no tomó bien el asunto, lo que generó algo de tensión con su madre. Posteriormente se le explicó a Violeta el tipo de organización horizontal que había asumido aquél espacio.

“Cuando mi mamá llegó, -rememora Isabel Parra- la Peña ya estaba lista y pa' mi mamá fue... fue la cosa más terrible, porque sus hijos en ese minuto se habían independizado y entonces quiso mandar el buque en la Peña y ahí se produjeron problemas tan graves como que no se hablaban (...)" (RODRÍGUEZ, 1984: 169).

Probablemente la cantautora veía en la idea allí desplegada una realización propia de sus hijos y sentía extraño el proyecto. Por otra parte, la impronta algo snob que iba adquiriendo el sitio parece haberle generado algo de incomodidad. La Peña de los Parra, recuerda Gastón Soublette "(...) se puso de moda y empezó a ir gente encopetada, del barrio alto. Tengo la impresión de que a ella no le gustó el ambiente que se había formado, y quiso hacer algo más popular, no tan pituco" (JURADO Y CARO, 2017: 25). En el mismo sentido Marta Orrego recordaba como Violeta

“(...) se ponía a vender discos en el mesón mientras hacían fila los pitucos (...). Llegaban y le decían a la Violeta 'a ver señora, en cuál de sus discos se cuenta mejor la tragedia de su vida' y ella tomaba el de Las Últimas Composiciones y les decía 'acá está'. Yo la retaba porque ella aceptaba que le preguntaran con esa frivolidad" (VALLADARES Y VILCHES, 2014: 88).

\section{La Carpa de la Reina}

Si bien Violeta continuó actuando esporádicamente en la Peña Carmen 340, el inicio de un proyecto propio parecía una consecuencia necesaria teniendo en cuenta la fuerte personalidad de la artista, quien difícilmente hubiera podido incorporarse asumiendo un protagonismo menor.

En septiembre de 1965 Sergio Larraín, un fotógrafo amigo de Violeta, le propuso participar en conjunto de un proyecto para montar una especie de peña dentro de la IV Feria Internacional de Santiago (FISA), en el Parque Cerrillos. Este era un gran evento donde se presentaban equipos industriales y agrícolas, novedades de equipamiento para el hogar, así como también artesanías. Para instalar lo planeado, Larraín compró en 
cuotas una carpa de circo que fue convenientemente nutrida de sillas y mesitas, además de otros implementos necesarios para su funcionamiento. A Violeta le colaboraron en el armado del emprendimiento sus hermanos Roberto y Lautaro, así como también su amado Gilbert.

La respuesta no fue la esperada. El público escaseaba y las disputas entre los socios decantaron en que Violeta terminó a cargo del asunto en solitario, agobiada por el esfuerzo y con deudas (SÁEZ, 2016). Más tarde Larraín intentó cerrar en buenos términos la sociedad buscando recuperar algo de la inversión inicial. Para Violeta ello fue una afrenta a la amistad y la ruptura fue inevitable (RODRÍGUEZ, 1984).

A partir de la posesión de la enorme carpa Violeta comenzó a vislumbrar el que sería su último proyecto de gran magnitud.

"Si bien los primeros meses Violeta participa activamente de La Peña de los Parra, no tardará en surgir la necesidad de dar pie a un proyecto propio. Alentada por el anhelo de forjar un Centro de Arte Popular, se entrevista con el entonces alcalde de La Reina, quien le entrega en concesión un lugar en el Parque La Quintrala" (PINOCHET COBOS, 2007: 43).

La idea era crear una "Universidad del Folklore", aprovechando la concesión que le otorgó el alcalde de la comuna de La Reina, Fernando Castillo Velasco, un arquitecto democristiano que tenía buenas relaciones con sectores de la izquierda. ${ }^{\text {iv }}$ La Reina era una comuna periférica de Santiago, recientemente creada y en pleno proceso de urbanización. Allí Violeta decidió poner en marcha su proyecto: un centro cultural que fuera un espacio privilegiado para la producción y difusión de la música folklórica. "El proyecto era muy ambicioso, lo redactó en un cuaderno de tapas negras -recuerda Isabel Parra- y se lanzó a pedirle colaboración a medio mundo" (PARRA, 2009: 207).

Con apoyo de algunas empresas privadas ${ }^{\mathrm{v}}$ Violeta Parra instaló la carpa circense en la calle La Cañada, dentro del parque La Quintrala que "Lo único que tenía de parque el lugar -recuerda Isabel Parra- eran unos álamos que porfiadamente habían resistido el paso de los inviernos" (PARRA, 2009: 141). ${ }^{\mathrm{vi}} \mathrm{El}$ parque, un triángulo de aproximadamente cuatro hectáreas, estaba delimitado por la calle Aguas Claras al norte, La Cañada al sur; mientras que por el oeste limitaba con Santa Rita y al este con Toro y Zambrano.

Violeta debió acondicionar el espacio para poder montar la carpa con un mínimo de comodidades para el funcionamiento.

"En el terreno donde estaba ubicada, -recuerda Jorge Aravena- habían sido talados todos los árboles (...) llevados a un aserradero y devueltos en tablas para el cerco, [y] la construcción del escenario, que después fue de cemento y piedras (...). Debieron cavar dos pozos profundos, uno para sacar el agua y otro para el servicio séptico. Con esa tierra emparejaron el piso que se conservó de tierra" (2017: 59).

El objetivo era crear su propio espacio, pero yendo más allá del modelo de peñas presentes hasta el momento. "La Carpa -según el cantautor Patricio Manns- parece el lugar apropiado y natural: se trata de una vieja carpa de circo amplia y circular, con un escenario y un modesto equipo de amplificación, capaz de albergar mil personas" (MANNS, 2017: 77). ${ }^{\text {vi }}$ Violeta Parra buscó insertarse en esa zona de las afueras de Santiago con un centro cultural donde las manifestaciones folklóricas se difundieran en todas sus formas. "Aquí voy a mostrar mis pinturas, -se entusiasmaba Violeta- mi arpillería, mis cerámicas, mis canciones” (MANNS, 2017: 78). una amplia difusión y proliferaban por doquier. De todas ellas, las cercanas a la canción 
popular de contenido político parecían gozar de mayor fervor y acompañamiento por parte del público. De forma que un espacio que reuniera dichas características, sumado a la fuerte presencia de una reconocida folklorista, a la vez innovadora en lo artístico y comprometida en lo político, parecía ser una fórmula ideal.

Con la ayuda de amigos y familiares, el viernes 17 de diciembre de 1965 Violeta finalmente inauguró La Carpa de la Reina.

“Tenía como unos cuarenta metros de diámetro y el escenario era un tabladito recuerda Carmen Luisa, tercera hija de Violeta- con una silla para cantar y algunos instrumentos [...]. En todo el medio de la carpa, donde queda, digamos, el palo mayor, estaba el fogón y desde por ahí empezaban las mesas en círculo mirando al escenario, sillas y mesas así en varias hileras, de modo que la gente quedaba como en un teatro" (SUBERCASEAUX Y LONDOÑO, 1976: 107).

Cada noche en la puerta de entrada a la carpa, Lautaro Parra, otro de los hermanos de Violeta, cobraba la entrada a cambio de una pequeña tarjeta que contenía la imagen de la cantautora. Este era el comprobante que la propia Violeta, al pasar a saludar a los asistentes por cada una de las mesas, pedía rigurosamente, evitando de esa forma que alguien ingresara sin pagar (ARAVENA LLANCA, 2017).

El escenario era bastante improvisado, pero de considerables dimensiones si se le compara con los pequeños tablados con que contaban la mayoría de las peñas. Se accedía por una pequeña escalinata y podía llegar a albergar hasta a 10 músicos. "Detrás estaba la habitación-dormitorio, oficina y recepción de Violeta la dueña de casa" (ARAVENA LLANCA, 2017: 63).

Este último dato es importante ya que Violeta llevó su apuesta al extremo y no solo quería desarrollar su amplia actividad artística en la carpa. Se trasladó a vivir allí junto a Carmen Luisa y Gilbert, de forma muy precaria en un pequeño espacio anexo.

“(...) su decisión de vivir en la carpa -recuerda su hija Isabel- era un rechazo absoluto a lo convencional. Un reencuentro con la tierra. No quería saber nada de 'alfombras ni de casas con brillante piso'. A veces con liviandad y otras con enorme violencia, nos reprochaba a nosotros, sus hijos, nuestra forma de vida aburguesada" (PARRA, 2009: 142).

De hecho, Violeta también fantaseaba con la posibilidad de trasladar a parte de sus familiares para vivir con ella en la carpa, en una experiencia comunitaria que excediera los marcos de la tarea artística. "Vámonos todos a la Reina -decía Violeta a su hija Isabelcon maridos, yerna [sic], nietas y animalitos. El lujo es una porquería, los seres humanos se consumen sumergidos en problemas caseros" (PARRA, 2009: 209). Para Ángel Parra, la posición de éxito alcanzada por él y los demás músicos a partir de la Peña Carmen 340, los ponía en una posición que Violeta no compartía.

“(...) fruto de nuestro trabajo con Marta Orrego, la madre de mis hijos, poseíamos una linda casa con todas las comodidades y un automóvil. Supongo que mi madre me juzgaba petit bourgeois. La contradicción debe haber sido enorme para ella, detestaba en lo que me había convertido". (PARRA; 2012: 26).

La decisión de Violeta contrariaba profundamente el perfil que estaban configurando muchos de los músicos que, al igual que hijos, comenzaban a contar con un relativo éxito económico y profesional en sus carreras. En una nota que Alfonso Molina Leiva realizara para el Suplemento Dominical del diario El Mercurio, el periodista se asombraba de que Violeta viviera en La Carpa:

"No estaba muy seguro de encontrarla allí porque pensaba que aquel lugar era sólo donde iba a cantar, creía que vivía en un departamento en el centro de Santiago, al 
igual que la mayoría de los artistas, en una casa llena de lujos (...). Pero no fue así. Me hicieron pasar a la parte trasera de la carpa donde se encuentra una casita de adobes, más bien dicho una pieza, sólo una, donde ella vive y que compone toda su casa" (EL MERCURIO 26/X/1966: 16).

\section{Una carpa demasiado lejos}

47 La idea general de Violeta excedía claramente el formato de peña que se había instalado en Santiago y las principales ciudades de Chile. Su apuesta era mayor y pretendía no cerrarse en un sitio orientado a las presentaciones artísticas. Inclusive la idea de Violeta iba más allá de la propia experiencia como centro cultural que se había puesto en práctica en la Peña Carmen 340. Así lo demuestra el impreso que se distribuyó el mismo día de la inauguración, donde además de la peña, presentaba La Escuela de Folklore. El impreso incluía ficha de inscripción y reseñaba las principales actividades a desarrollar y los docentes a cargo de cada uno de los cursos.

La oferta se dividía en dos áreas: Artes Plásticas (cerámica, escultura y pintura) y Folklore (guitarra y danzas). Teresa Vicuña, Margot Guerra y la propia Violeta Parra eran anunciadas como las docentes del área plástica, mientras que los cursos de música y danza serían dictados por Margot Loyola, Raquel Barros, Gabriela Pizarro, para los adultos; y Silvia Urbina, Rolando Alarcón e Hilda Parra para los cursos orientados para niños.

Osvaldo Cádiz recuerda que a pesar del impulso de Violeta y de la importancia de los nombres de los profesores, los cursos nunca pudieron dictarse: “(...) no se inscribió gente, no hubo alumnos interesados. Ella hizo estos programas que se repartieron en papel grueso, casi como un programa de teatro" (JURADO Y CARO, 2017: 26). Según el mismo Cádiz, para la Universidad de Folklore, Violeta se habría inspirado en los Cursos de Temporada universitarios, donde ella y, principalmente, Margot Loyola habían participado (JURADO Y CARO, 2017).

50 A pesar de los buenos pronósticos previos la experiencia de La Carpa resultó fallida. La ubicación geográfica resultó determinante para el fracaso de esta peña, ya que al estar muy alejada del centro de la ciudad eran pocos los que se aventuraban hasta la comuna. "La gente que visitaba La Carpa -sostiene Aravena- era toda gente acomodada que llegaba en auto o en taxi (...) llegar hasta allí no era fácil puesto que no había micros cercanas" (2017: 74). El sistema de transporte por aquél entonces no ofrecía demasiadas alternativas hacia La Reina, y para aquellos que no poseían movilidad propia el retorno al hogar en altas horas de la noche era poco menos que imposible.

51 Gloria Fernández era por ese tiempo una joven estudiante universitaria habitué de las peñas santiaguinas. Las veces que pudo concurrir a La Carpa de la Reina lo hizo a partir de que varios asistentes se ponían de acuerdo y compartían la movilidad. "Para retornar lo más cercano para conseguir algo de movilidad era ir hasta [Avenida] Larraín. En varias ocasiones nos llevó un señor en su automóvil hasta Plaza Egaña. Desde allí era un poco más fácil" (FERNÁNDEZ, comunicación personal, septiembre 2017). Esta dificultad que entrañaba el traslado a La Carpa parece haber sido uno de los elementos determinantes para que la experiencia fracasara.

El traslado hacia la Carpa parecía significar un plan único para una salida nocturna, mientras que las peñas céntricas ofrecían no solo un acceso más cómodo sino la opción de movilizarse por varias de ellas. "El circuito de peñas, -refiere Gloria Fernández- como la 
de los Parra o las universitarias, permitían que uno pudiera ir un poco a cada una. Una se encontraba con amigos, con compañeros de estudio... podía luego ir a tomarse un copete a otro lugar y así..." (FERNÁNDEZ, comunicación personal, septiembre 2017).

A pesar de contar con un importante número de artistas invitados (actuaron allí Quilapayún, Osvaldo Rodríguez, Margot Loyola, el grupo boliviano Los Jairas), además de la propia Violeta, la afluencia de público fue variable. "La Carpa de la Reina abre sus puertas al público en diciembre de 1965, pero la euforia con que fue acogida su presentación inicial termina diluyéndose en largas noches con escaso público y quejas de los vecinos" (PINOCHET COBOS, 2007: 43).

De esta forma, algunas noches La Carpa podía desbordarse de gente, o bien, como en no pocas ocasiones, estar absolutamente vacía. "Había días en que no había nadie rememoraba años después Carmen Luisa- y otros en que me volvía loca porque era la única que atendía y tenía que andar haciendo acrobacias" (SUBERCASEAUX Y LONDOÑO, 1976: 108).

Poco a poco los días en que la concurrencia era mínima comenzaron a ser más frecuentes. Sin embargo, "Aunque no hubiera nadie, a la hora de la función tanto los grupos como Violeta hacían su actuación. (...) un atónito Pedro Messone presenció una actuación de Violeta en la Carpa cantando sin público" (GONZÁLEZ, ROLLE Y OLSHEN, 2009: 236). Carmen Luisa asegura que Violeta esperaba con impaciencia la llegada del público hasta las 12 de la noche, “(...) yo me iba a mi pieza segurísima de que mi mamá no dormiría en toda la noche, tratando de explicarse por qué pasaba esto" (SUBERCASEAUX Y LONDOÑO, 1976: 109).

Jorge Aravena Llanca, quién estuvo colaborando unos meses en La Carpa, señala que en algunas ocasiones Violeta, luego de cerrar se trasladaba a la peña céntrica de sus hijos. El contraste era devastador: "La Peña de Carmen 340 siempre llena -señala Aravena- le producía, sin duda, envidia o un malestar indigerible (...)" (2017: 58).

57 Más allá de las complicaciones a la hora de atraer público, se puede vislumbrar una especie de reacción en Violeta ante la modernización que implícitamente empañaba las relaciones entre artistas y medios de comunicación. Si bien la Carpa de la Reina y las demás peñas, incluida la que administraban sus hijos, compartían la presencia de muchos de los mismos artistas, la canción protesta y el sesgo militante parecieron dictar el pulso en muchas peñas citadinas. La apuesta de Violeta, no exenta de compromiso social, parecía no cerrarse en ese único precepto y aspiraba a ideales más afines con muchos de los aspectos propios de su carrera artística.

La experiencia de las peñas fue un fenómeno que no estuvo ajeno a ciertas tensiones con el público asistente, lo que producía una relación ambivalente. En el caso particular de La Carpa, si bien Violeta necesitaba por cuestiones artísticas y económicas la más amplia concurrencia de público, muchas veces sus actitudes fueron claramente poco amistosas para con aquellos asistentes que no parecían responder a los cánones aceptados por la artista. "Cuando Violeta -recuerda Sergio Larraín- se daba cuenta que estaba entre un público snob se volvía tremendamente agresiva, casi provocadora [...]" (SUBERCASEAUX Y LONDOÑO, 1976: 112-113).

59 A estas dificultades se añadían sus relaciones poco amigables con el entorno a pesar de que Violeta contaba con el apoyo de la Junta de Vecinos y con el aval del alcalde. Buena parte de los habitantes de La Reina, un sector en desarrollo que pretendía ser residencial, no veían con buenos ojos la instalación de La Carpa. "A los vecinos de La Reina -remarca 
Carmen Oviedo- no les hace gracia verla amasando y friendo sus empanadas; este sector residencial se opone con dientes y muelas a la actividad de la folclorista" (OVIEDO, 1991: 104).

Durante el tiempo que funcionó La Carpa fueron constantes las denuncias y acusaciones de los vecinos. Carabineros allanó reiteradas veces el local y la propia vivienda de Violeta ante las denuncias de que expendía bebidas alcohólicas sin autorización (PARRA, 2009). Alberto Zapicán, un artesano bohemio de nacionalidad uruguaya, estuvo una temporada colaborando con los quehaceres y mantenimiento de la carpa. ${ }^{\text {viii }}$ En algunos de sus relatos ha dejado constancia de muchas de las dificultades que encontró Violeta por aquellos días. Incluso Zapicán relaciona la militancia política de la folklorista con las trabas que encontró para poder mantener a flote su proyecto.

61 "Cortaban la luz, había que hacer trámites para reponerla y eso nomás llevaba semanas, a veces la enganchábamos a lo bandido. (...) permanentemente llegaban carabineros a revisar todo. (...) Había un par de regidores, un tal Berg y un tal Dupré que le mandaban la policía, todo por ser izquierdista" (SUBERCASEAUX Y LONDOÑO, 1976: 116).

62 La tensión fue in crescendo, y finalmente un tirador anónimo del vecindario mató a la llama que pastaba al costado de la carpa, espécimen que Violeta había traído de un viaje a Bolivia.

Para Víctor Herrero (2017) el fracaso del proyecto de La Carpa a partir de los vaivenes de público y la imposibilidad de desarrollar los cursos programados por la falta de inscriptos, dejaba la dolorosa evidencia que Violeta había descubierto apenas regresó de Europa, esto es, que la música de raíz folklórica, a la cual ella le había dedicado muchos años, ya no formaba parte del repertorio ni del interés de los músicos más jóvenes, ni siquiera a sus hijos $\mathrm{y}$, menos aún, del público.

Sin embargo, creo que debe matizarse esa idea. Si bien esta música sufría el avance de otros géneros y estilos musicales, tal como se planteó al inicio de este trabajo, cada una de las vertientes en que había decantado la música de raíz folklórica en Chile: el Tradicionalismo, la Proyección folklórica y la renovación (vía Neofolklore o la incipiente Nueva Canción), tenían sus propios ámbitos, audiencias y espacios de circulación. Por supuesto, no todos con los mismos alcances y repercusiones. De hecho, la tarea emprendida por Violeta Parra y Margot Loyola tenía continuadores, en cierto modo, con la tarea desarrollada por algunos solistas como Víctor Jara, Rolando Alarcón, Héctor Pavez, Gabriela Pizarro y por los grupos Cuncumén, Millaray y Henchullán, éste último apadrinado por la propia Violeta en su etapa de La Carpa. Estos artistas, siguiendo su propio camino, veían a la labor de Violeta como una inspiración y buscaban compatibilizar las tareas de recopilación y rescate del folklore tradicional con la conformación de una carrera artística dentro del mercado.

Lo cierto es que la poca repercusión de la Universidad del Folklore, sumado a la escasa afluencia de público fueron mellando el ánimo de Violeta. Si bien su vida entera había sido una lucha constante para sobreponerse como artista a las dificultades que el medio le ofrecía, el fracaso de este proyecto, sumado a múltiples problemas emocionales fueron sumiéndola en la depresión. 


\section{Una carpa demasiado gigante}

66 de manejar un sitio de tales características, ya que contaba con escasa colaboración.

“(...) era una tarea excesiva -relata Carmen Oviedo- para una sola persona: había que encender el fogón central y los braseros para la calefacción en invierno, cocinar a leña las empanadas y anticuchos que ofrecía al público, preparar la mistela y el mate y estar pendiente de todos los detalles, además de tener que cantar y bailar" (OVIEDO, 1991: 103).

67 Teresa Vicuña, amiga de Violeta, afirma que la cantautora fue advertida de las dificultades que acarreaba el mantenimiento de La Carpa, pero sin embargo poco caso hizo a los avisos: “¡Sí, todo el mundo le dijo! Pero ella era, como dicen en el campo, llevada de su idea. No escuchaba. Y sus hijos, bueno, estaban en lo de ellos. Y Violeta era buena para escabullirse si nosotros la queríamos hacer entrar en razón" (JURADO Y CARO, 2017: 26).

Para Jorge Aravena la carpa estaba muy dañada, resultaba muy difícil recuperarla y el deterioro deslucía el proyecto: “Cuando la conocí por primera vez no comprendí que ahí dentro se pretendiera comunicar con el canto y la música acciones artísticas, pues era un espacio demasiado grande, frío, feo y deprimente" (ARAVENA LLANCA, 2017: 61).

Algunos amigos y familiares, sin embargo, oficiaron de auxilio en momentos en que el proyecto parecía colapsar.

“Todos quisimos ayudar -rememora la escultora Teresa Vicuña-. Pero no funcionó porque la gente no llegaba, hacía mucho frío siempre. Habían hecho unos braseritos preciosos para calentarse, pero nunca hubo gente que llenara eso" (JURADO Y CARO, 2017: 26).

70 Héctor Pávez, un antiguo discípulo, colaboró por un tiempo con ella en la organización diaria de La Carpa, que era cada vez más difícil (SUBERCASEAUX Y LONDOÑO, 1976). Pero más allá de las eventuales colaboraciones Violeta adolecía de que sus compañeros artistas no la acompañaban lo suficiente y que la prensa no difundiera sus actividades. Nora Ferrada le realizó una entrevista para la revista Ecran a principios de 1966 y se encontró con una Violeta que le espetó la desatención de la prensa: “¡Ahora me viene a ver! ¡Tanto que he invitado a la radio y a la prensa a visitar mi carpa! (...) ¡No pretendo actuar y hacer funcionar todo para que disfruten las sillas nomás!" (ECRAN 1825: 37).

71 El equilibrio emocional de Violeta parece haber sido muy precario por aquél entonces, algo nada aconsejable para administrar en forma solitaria un proyecto de vastas dimensiones y con altas dosis de dificultad. Asimismo, Violeta Parra sufría de una erupción cutánea de origen nervioso que la tenía muy molesta, por lo cual la cantautora ingería pastillas para mitigar la comezón. “(...) la alergia no me deja vivir”, refería la propia Violeta en la citada nota a Ecran (1825: 37). ix

72 Sin querer hacer aquí un psicologismo histórico barato, es posible vislumbrar en la reconstrucción de ese último año de vida de Violeta la presencia de fuertes contrastes. A los momentos de excitación y planificación de múltiples proyectos artísticos seguían períodos de depresión personal y frustración profesional. "Bulle de actividad cuando no está deprimida (...)", narra Oviedo (1991: 104) y se entusiasmaba con la actividad de La Carpa cuando había concurrencia:

"El sábado -relataba Violeta en una carta a Gilbert Favre- tuve 150 personas en la carpa. Tenemos comida para el público: asaditos, empanadas fritas, sopaipillas 
pasadas, caldo, mate, mistela y música (...) Todo el mundo tomando mate en la carpa. ¡Qué maravilla es mi carpa ahora!" (PARRA, 2009: 208). amigo Osvaldo Rodríguez, quién había llevado a Zapicán a La Carpa, Violeta se quejaba amargamente de las dificultades que la acosaban y, de paso, descargaba su furia contra el uruguayo:

"Por aquí han pasado decenas de tipos, a los que la carpa los acompleja y se los traga. Creía que Alberto con su aire de león era el único que la dominaría. Pero la carpa no tiene ni un solo hombre. Nadie ha sido capaz para ella (...). Sólo yo soy capaz de resistirle. No puede ser, Osvaldito" (PARRA, 2009: 214).

79 La Carpa, los problemas amorosos, o bien las grandes dificultades de su vida artística y familiar llevaron a Violeta a la terrible decisión de quitarse la vida. Luego de un duro invierno y de tener que mantener casi en soledad el funcionamiento de La Carpa, el 5 de febrero de 1967 Violeta se suicidó de un disparo en la sien.

“(...) el fracaso de la carpa -sostiene Patricia Vilches- equivale a un naufragio artístico, que a la vez, en el más puro estilo idealista de Violeta, adquiere garra y se convierte aquel fatídico 5 de febrero, 1967 -y para la posteridad- en un punto neurálgico de la sociedad chilena, en un barómetro social que descifra el lugar de Violeta en la memoria colectiva Chilena" (VILCHES, 2013: 64). 


\section{Modernización y arcaísmo de La Carpa}

80 una zona tan alejada para llevar adelante su proyecto cultural, aspecto, entre otros, que pareció determinante para el fracaso. Es probable, entre otras posibles causas, que la elección no haya sido fruto de múltiples alternativas sino, más bien, producto de la decantación. Al parecer Violeta Parra presentó su proyecto en varias comunas y solamente encontró respaldo del alcalde Castillo Velasco para plantar la carpa en La Reina.

Según Víctor Herrero (2017), Violeta había contactado al alcalde a través de Camilo Fernández, el conocido productor discográfico que había lanzado a través del sello Demon, los discos de la Peña de los Parra. Fernández, al conocer los deseos de Violeta de abrir su propio local, la estimuló para avanzar con su idea y le presentó a Castillo Velasco.

Por su parte, Paula Miranda interpreta que La Carpa en sí “(...) reproducía la disposición del espacio esférico de la ruka y la centralidad del fogón; de él se sacaban pequeños braseritos que eran puestos en las mesas, multiplicando su calor" (2017:146). Es decir que la opción tomada por Violeta, más allá de la propia coyuntura particular que depositó en su poder a aquella desvencijada carpa amarilla, y de su elección también vinculada a su pasado circense, podría estar vinculada al contacto con el mundo mapuche.

"Esa imagen la adquirió -continúa Miranda- en parte y sin duda de la visita que realizó a la ruka de la machi María Painen Cotaro, de quien aprendió lo más fundamental de esa cultura: su sentido espacial y culinario; su circularidad y la dimensión medicinal de la palabra, tanto del canto y del kultrung" (2017:146).

Por otro lado, no hay que descuidar el hecho de que la artista eligió una carpa circense como espacio donde materializar una propuesta que, en buena medida, se posiciona como diferente a la desplegada por las peñas situadas en el casco urbano. Tal vez el intento de Violeta Parra era producir, a partir de una matriz común, un fenómeno absolutamente diferente. Mientras que en su juventud había migrado desde el campo hacia el espacio urbano, en La Carpa, situada en la Reina Alta, un sector por entonces poco urbanizado de Santiago y con características similares al ámbito rural, Violeta parece querer realizar una especie de retorno a los orígenes. De esa forma transgredía la tendencia dominante a partir de una especie de parábola. Claro que ese retorno tenía mucho de impostado, que es lo que refuerza en sí a la transgresión.

"El hecho de querer vivir -remarca Juan Pablo González- en una habitación con piso de tierra, no es algo que un campesino quiera hacer si tiene los medios como para ponerle madera al piso, entonces también hay un gesto de Violeta de voluntad, que puede ser leído como 'contracultural' (...)" (GONZÁLEZ, 2017: 246).

En todo caso, Violeta Parra respondía a influencias diversas, y en algún punto, contrapuestas. Si el formato de peñas inaugurado en Carmen 340 podía ser catalogado de novedoso, y emparentado con aquellas boites de nuit parisinas que los Parra habían frecuentado a inicios de los años 60 , el formato también respondía a múltiples tradiciones vernáculas, entre ellas las antiguas casas de canto, las fondas y las chinganas, formas antiguas de sociabilidad vinculadas a la música tradicional en Chile.

En este sentido, las peñas podrían ser pensadas como una conjunción entre tradición y modernidad, un anclaje en el espacio físico que permitía materializar en parte la actitud musical, estética y performativa de determinados solistas y conjuntos en post de una 
renovación de la música popular. Pero tensando aún más el argumento, la apuesta de Violeta Parra en La Carpa de la Reina, si bien apelaba a la matriz modernizante de las peñas, lo hacía casi en un formato opuesto, con característica arcaizantes, ajustándose a un primitivismo plasmado tanto en la ubicación periférica y casi rural (la Reina Alta) y en el formato (una precaria carpa circense). simpatizante de izquierda, fueron transformándose en ámbitos de sociabilidad que posibilitaron asumir un sistema de valores en buena medida compartidos. Estos valores, al alcanzar su realización en un espacio desestructurado donde el entretenimiento y el 
goce estético se presentaban como los objetivos inmediatos, posibilitaron la empatía entre artistas, obra musical y auditorio.

En buena medida podemos señalar a las peñas folklóricas surgidas en el Chile de mediados de los años 60 como una de las formas en que se materializó la sociabilidad de determinados sectores de la izquierda vinculados a la intelectualidad y la cultura. Las peñas folklóricas constituyeron espacios con una serie de pautas propias y diferenciadas, que instalaron una dinámica distintiva diferenciada de otros modelos de la sociabilidad proletaria o pequeño-burguesa.

los elementos reseñados en este trabajo, resulta evidente que La Carpa de la Reina no funcionó como un ámbito del mismo estilo que las peñas. La militancia de izquierda, y los sectores juveniles que colmaban los espacios de las peñas santiaguinas, no asistieron en gran número a La Carpa de la Reina, quizás debido a las dificultades de acceso mencionadas. También es posible que ese ámbito agreste de la carpa de circo y la apuesta para nada snobista de Violeta Parra no resultara del todo atractiva para aquellos sectores urbanos y bohemios. Peñas como la regenteada por los hijos de Violeta, las peñas universitarias u otras, parecían resultar más seductores para aquél público.

Enmarcar a La Carpa de la Reina dentro del fenómeno de las peñas puede parecer, entonces, excesivo. Este espacio complejo y múltiple guardó muchas similitudes con el fenómeno de las peñas, pero también escapó del marco de dichos ámbitos. Si bien la propuesta parecía compartir los postulados generales de los otros sitios, su esencia fue marcadamente diferente. Quizás hasta podemos ir más lejos en el análisis y llegar a plantear que, en el fondo eran propuestas antagónicas, tanto en el contenido como en la forma. La reconversión de espacios propiamente urbanos, como una vieja casona, un local abandonado o el propio ámbito universitario no se correspondieron con la idea de Violeta, quien eligió una carpa circense (más precaria aún que los precarios espacios mencionados) en un sector alejado del área céntrica buscando tal vez desmarcarse del componente netamente citadino y cosmopolita de la peña.

La Carpa de la Reina, en definitiva, fue una especie de reacción contra los sistemas de producción y difusión artística, inmersos en un profundo cambio, donde cada vez se notaba más presente la mercantilización del artista y su obra. Asimismo, el fuerte sesgo citadino que poseían las peñas céntricas (donde la escenografía apelaba a un imaginario rural o marítimo,) no dejaba de ser una postura artificiosa, que solo ofrecía marco a una música de raíz folklórica fuertemente mediatizada y por lo tanto de corte urbano.

Esencialmente lo que Violeta Parra estableció en La Carpa de la Reina fue un gesto primitivista, un giro brutal, una búsqueda desesperada de una alternativa a las formas establecidas de producción y difusión del hecho artístico que, en última instancia, también se contraponía al carácter esencialmente bohemio, urbano, intelectual y hasta snobista de las peñas folklóricas. 


\section{BIBLIOGRAFÍA}

AGULHON, Maurice (1966), La sociabilité méridionale. Confréries et associations dans la vie collective en Provence orientale la fin du XVIIIe siècle, Le Pensée universitaire, Aix-en-Provence. AGULHON, Maurice (1992), "La sociabilità corne categoria storica”, Dimensioni e problemi della ricerca storica, Núm. 1, pp. 39-47.

ARAVENA LLANCA, Jorge (2017), Lo visible indecible en Violeta Parra. Un mito de iniciación obsesiva, Palabra e imagen, Santiago.

CASAUS, Víctor (2009), “Artista y público: el milagro del contacto”, en Parra, Isabel El libro mayor de Violeta Parra. Cuarto Propio, Santiago.

FERRADA, Nora “Violeta Parra y su drama”, Revista Ecran, Núm. 1825, 25 enero 1966.

GONZÁLEZ, Juan Pablo (2017), “Lo popular, la música popular y sus tensiones”, Revista Observatorio Cultural. Edición Especial, agosto 2017, pp. 247-249.

GONZÁLEZ, Juan Pablo; ROLLE, Claudio y OLSHEN, Oscar (2009), Historia social de la música popular en Chile. 1950-1970, Ediciones de la Universidad Católica de Chile, Santiago.

HERRERO, Víctor (2017), Después de vivir un siglo. Una biografía de Violeta Parra, Lumen, Santiago.

JARA, Joan (2009), Víctor un canto inconcluso, Lom, Santiago.

JURADO, María Cristina y CARO, Sergio (2017), “El último amor de Violeta”, Revista Ya. El Mercurio, 21/II/2017, pp. 24-27.

MAMANI, Ariel (2013), “Peñas, canción de protesta y transformación política en Chile (1965-1973)”, Música Popular em Revista, Año 1, Vol. 2, pp. 121-147.

MANNS, Patricio (2017 [1977]), Violeta Parra, la guitarra indócil, Lumen, Santiago.

MIRANDA, Paula (2017), "Violeta Parra y su encuentro pleno con el canto mapuche: impacto y nuevos sentidos en su poesía”, Revista Observatorio Cultural. Edición Especial, agosto 2017, pp. 139-160.

OVIEDO, Carmen (1991) Mentira todo lo cierto: Tras la huella de Violeta Parra, Editorial Universitaria, Santiago.

PARRA, Ángel (2012 [2006]), Violeta se fue a los cielos, Catalonia, Santiago.

PARRA, Ángel (2016), Mi Nueva Canción Chilena. Al pueblo lo que es del pueblo, Catalonia, Santiago.

PINOCHET COBOS, Carla (2007), Violeta Parra. Hacia un imaginario del mundo subalterno, Tesis de Licenciatura inédita, Universidad de Chile, Santiago.

RODRÍGUEZ, Osvaldo (1984), Cantores que reflexiona. Notas para una historia personal de la Nueva Canción Chilena, LAR, Madrid.

SÁEZ, Fernando (2016), La vida intranquila. Biografía esencial de Violeta Parra, Planeta, Santiago. SANTANDER, Ignacio (1984), Quilapayún, Ediciones Júcar, Barcelona. 
SUBERCASEAUX, Bernardo y LONDOÑO, Jaime (1976), Gracias a la vida. Violeta Parra, Testimonio, Galerna, Buenos Aires.

VALLADARES, Carlos y VILCHES, Manuel (2014), Rolando Alarcón. La canción en la noche, El Natre, Santiago.

VILCHES, Patricia (2013), "Violeta se fue a los cielos de Andrés Wood: El naufragio de La Carpa de La Reina”, Revista Internacional d'Humanitats, Núm. 29, sept-dic 2013, pp. 63-80.

\section{ANEXOS}

\section{Prensa:}

- El Musiquero, Núm. 116, 1970.

- El Musiquero, Núm. 19, julio 1965.

- Suplemento Dominical del diario El Mercurio 26 de octubre 1966.

\section{Cinematografía:}

- Wood, Andrés Violeta se fue a los cielos, Agência Nacional do Cinema (ANCINE)-Instituto Nacional de Cine y Artes Audiovisuales (INCAA)(colaboración); Maíz Producciones; Wood Producciones, 2011.

\section{NOTAS FINALES}

i. Más sobre las peñas a mediados de los 60 en MAMANI 2013.

ii. Hay que destacar que el repertorio también se nutría de otro tipo de canciones cuya temática y contenidos no eran necesariamente militantes o comprometidas.

iii. En un libro reciente, producto de la catarata de publicaciones referidas a Violeta Parra a partir del centenario de su nacimiento, Víctor Herrero (2017) pone en duda el origen humilde de la familia Parra, presentándolos como parte de una clase media provinciana, sin demasiados recursos, pero lejos de aquella imagen de miseria legada por muchos de los miembros del clan Parra.

iv. Los hijos de Castillo llegaron a ser militantes del MIR. El propio Castillo llevó adelante durante la dictadura una importante tarea en defensa de los derechos humanos, lo que le valió conflictos en el seno de su propio partido, la persecución del régimen militar y algunos años de exilio.

v. La empresa de energía Gasco S.A y Sanitarios Escobar (GONZÁLEZ; ROLLE y OLSHEN, 2009).

vi. Según Jorge Aravena Llanca (2017) La Cañada 132 era la dirección por entonces. El resto de autores consigna La Cañada altura 7200 y hoy forma parte de una zona completamente urbanizada donde sólo hay una idea vaga de la ubicación de la carpa.

vii. Otras fuentes señalan entre 400 a 600 personas la capacidad que albergaba la carpa. De todas formas, el número podría ser variable debido a que la propia estructura de la carpa podría permitir una mayor cantidad de asistentes.

viii. Su verdadero nombre era Alberto Giménez Andrade. Utilizaba el apellido Zapicán, nombre de la localidad de donde era oriundo en Uruguay. 
ix. Más sobre la alergia nerviosa en Aravena Llanca (2017); también el testimonio de Carmen Luisa en Rodríguez (1984).

\section{RESÚMENES}

A mediados de los 60 se produjo en Chile la proliferación de peñas folklóricas donde se presentaban números musicales en vivo. Por aquellos años Violeta Parra retornó a Chile y decidió sumarse al fenómeno a partir de una "peña" poco convencional, La Carpa de la Reina.

El presente artículo analiza la faz artística, cultural y política de este emprendimiento montado por Violeta meses antes de poner fin a su vida. A partir de ello se buscará dar respuesta a diferentes interrogantes que determinen si La Carpa fue continuidad y punto climático de la experiencia de peñas folklóricas o sí esta idea desarrollada por Violeta Parra resultó una propuesta antagónica tanto en el contenido como en la forma.

À partir de 1965 au Chili, on a vu proliférer des établissements où se présentaient des chansons folkloriques en direct. C'est à cette époque que Violeta Parra retournait à son pais, et décidait de se joindre au phénomène à partir d'un espace peu conventionnel, La Carpa de la Reina. Le présent article analyse l'importance artistique, culturelle et politique de cette entreprise montée par Violeta. Il s'agira de déterminer si La Carpa a été une continuation de l'expérience des espaces folkloriques ou une proposition totalement différente.

sociabilité - Violeta Parra - Chili - peñas - musique

\section{ÍNDICE}

Palabras claves: sociabilidad - Violeta Parra - Chile - peñas - música

\section{AUTOR}

\section{ARIEL MAMANI}

Universidad Nacional de Rosario - Universidad Autónoma de Entre Río. Historiador argentino, ha concentrado su trabajo historiográfico en los vínculos entre cultura, arte y política en la $2^{\mathrm{a}}$ mitad del siglo XX, realizando tareas de investigación sobre temas específicos de Chile y Argentina. También ha realizado estudios musicales de nivel superior, especializándose en música latinoamericana y argentina, realizando investigaciones de carácter musicológico y de historia de la música. 